\title{
Lubrication and Anti-Rust Properties of Jeffamine-Triazole Derivative as Water-Based Lubricant Additive
}

\author{
Jiabei Wang ${ }^{1,2}$, Wenjing $\mathrm{Hu}^{1, *}$ and Jiusheng $\mathrm{Li}^{1, * \mathbb{D}}$ \\ 1 Laboratory for Advanced Lubricating Materials, Shanghai Advanced Research Institute, \\ Chinese Academy of Sciences, Shanghai 201210, China; wangjiabei2019@sari.ac.cn \\ 2 University of Chinese Academy of Sciences, Beijing 100049, China \\ * Correspondence: huwj@sari.ac.cn (W.H.); lij@@sari.ac.cn (J.L.)
}

Citation: Wang, J.; Hu, W.; Li, J. Lubrication and Anti-Rust Properties of Jeffamine-Triazole Derivative as Water-Based Lubricant Additive. Coatings 2021, 11, 679. https:// doi.org/10.3390/coatings11060679

Academic Editor: Rubén González

Received: 7 May 2021

Accepted: 2 June 2021

Published: 4 June 2021

Publisher's Note: MDPI stays neutral with regard to jurisdictional claims in published maps and institutional affiliations.

Copyright: (c) 2021 by the authors. Licensee MDPI, Basel, Switzerland. This article is an open access article distributed under the terms and conditions of the Creative Commons Attribution (CC BY) license (https:/ / creativecommons.org/licenses/by/ $4.0 /)$.

\begin{abstract}
With the worldwide concern of environmental protection, water-based lubricants exhibit extensive potential applications due to their advantages of energy-conservation, innocuity, and competitive price. Nonetheless, the common lubricating additives currently available in the market are mainly oil-based, while multifunctional water lubricants are rare. This paper reports a sulfurand phosphorus-free multifunctional additive with high water-solubility, which is applicable for multitype material surfaces. Specifically, through the Mannich reaction method, a Jeffamine-triazole derivative was synthesized from olyetheramine and benzotriazole. Compared with distilled water, the derivative exhibited superior friction reduction and wear resistance properties in water, with the friction reduction rate up to $72.7 \%$ and $70.2 \%$ for steel/steel and steel/aluminum contacts, respectively, when the concentration of the JD2000 is $2 \mathrm{wt} . \%$. Remarkably, the wear resistance property for steel/aluminum contact is improved by $88.2 \%$. Moreover, the additive showed corrosion inhibition on the metal surface by $75.5 \%$. We further revealed the lubrication and anti-rust mechanisms: the additives are adsorbed on the surfaces through nitrogen atoms, and the long-chain structure of polyether can cover the sliding surfaces, forming a stable viscoelastic film to prevent the severe damages caused by the direct contact between rough friction pairs. Concurrently, the dense protective film can resist the corrosion of environmental media on the metal surface and delay the metal rust. This research may provide a candidate for an ecofriendly multifunctional water-based lubricating additive.
\end{abstract}

Keywords: water lubrication; multifunctional ecofriendly additive; tribological property; corrosion inhibition performance

\section{Introduction}

With the severe situation of environmental problems and the worldwide shortage of oil resources [1], traditional lubricants and greases are facing serious challenges. It is imperative to develop new strategies of realizing multifunctional "green" lubrications. As a novel type of ecofriendly lubrication method, water lubrication exhibits a wide application prospect in drilling equipment, tail bearing, metal tool processing, etc. due to its advantages of low cost, high thermal conductivity, high fluidity, and environment friendliness [2]. However, the development of water-based lubrications is limited by the problems of low viscosity, poor lubrication performance, and serious corrosion [3]. Additionally, most lubricating additives are applicable for oil or greases, while water-based additives are relatively few [4]. Commonly used water-based additives have some unavoidable shortcomings. Borate, for example, has poor solubility in water and cannot play a good role in lubrication. Sulfur and phosphorus additives contain active elements, which can easily cause environmental pollution, such as water eutrophication. Relevant environmental laws and regulations have clearly banned the use of phosphorus compounds [5]. In addition, the preparation of nano-water-soluble additives is generally complicated and costly. Therefore, it is very important to promote the development of water-based lubricants to obtain green 
multifunctional lubricating additives with good lubricity and anti-rust properties through a simple preparation method [6].

Water-soluble polymer additives, especially the polymers with polar groups, have gradually attracted the attention of researchers [7]. According to the principle of coordination chemistry, the polar group containing a lone pair of electrons can be combined with the empty d orbital of the metal ions through coordination bonds, forming a stable complex, thereby realizing the firm adsorption of the polymer on the rough metal surface and deposition to form multiple closely arranged molecular layers to prevent direct contact with rough surfaces [8-11]. When the friction pairs are sheared mutually, the loosely bonded outer molecules between the layers are easily cut off, realizing an effective lubrication [12]. Meanwhile, the stable adsorption of the protective film can promote the abilities of anti-rust and anti-corrosion as well. Desanker et al. [13] prepared a series of nitrogen heterocyclic friction modifiers, which can enhance surface adsorption through chelation. Relevant studies have confirmed that nitrogen-containing polar groups have outstanding performance in the adsorption of polymers and metal surfaces.

Under mild rolling or sliding conditions, lubricant additives' molecules in a formulated lubricant help mitigate friction and wear in the boundary lubrication regime [14]. Benzotriazole is a kind of commonly used industrial corrosion inhibitor, which can react on various metal surfaces to form an insoluble anti-rust layer and achieve corrosion inhibition effect [15]. Jeffamine with high molecular weight is commonly used as a gasoline detergent, which has excellent detergency, dispersion, demulsification, corrosion inhibition, and anti-oxidation properties. It can also remove the original CCD (deposits formed in the combustion chamber of the engine) without generating sediment itself [16]. These two common industrial machinery materials are insoluble in water at room temperature and cannot be used in the water lubrication field. Based on the above background, we used water-insoluble Jeffamine (2000) and benzotriazole as raw materials to synthesize a sulfur- and phosphorus-free water-soluble Jeffamine-triazole derivative (JD2000) through the Mannich reaction. The structure and molecular weight distribution of the additive were characterized by MALDI-TOF mass spectrometer, Fourier transform infrared spectrometer, nuclear magnetic resonance equipment, and gel permeation chromatograph. The adsorptive and anti-rust properties of the JD2000 onto metal surfaces were evaluated by water contact angle tests and iron scraps tests. Furthermore, the tribological properties of the water-based additive on different metal surfaces were investigated. To verify the adsorption of the JD2000 on metal surface, quartz crystal microbalance with dispersion was used to study the adsorption behavior. The composition and chemical state of the worn surface are important in explaining the relationship between the molecular structures and tribological properties of the additive. Therefore, X-ray photoelectron spectroscopy, white light interference method, scanning electron microscope, energy dispersive spectrometer, and MALDI-TOF mass spectrometer were used to analyze the worn traces. Based on the results of tribological experiments, adsorption behavior test, and surface analysis, we clarified that the adsorption performance of the additive on the metal surface promotes the tribological performance and the anti-rust property.

\section{Materials and Methods}

\subsection{Materials}

The analytical reagents, Jeffamine D2000 and benzotriazole, were purchased from the Shanghai Titan Scientific Co., Ltd., Shanghai, China. The formaldehyde, sodium hydroxide, and sulfuric acid were purchased from the Sinopharm Chemical Reagent Co., Ltd., Shanghai, China. To ensure easy commercialization, all of the raw materials can be obtained from the commercial market without further purification.

\subsection{Preparation of the JD2000}

The JD2000 derivative were prepared via the following procedures. First, the benzotriazole $(1.25 \mathrm{~g}, 10 \mathrm{mmol})$ was introduced into the sodium hydroxide solution (8 wt.\%, 
$100 \mathrm{~mL})$. Then, a Jeffamine D2000 (21.05 g, $10 \mathrm{mmol})$ and $37 \mathrm{wt} . \%$ formaldehyde solution $(0.85 \mathrm{~g}, 10 \mathrm{mmol})$ were added under magnetic stirring. The mixture was heated to $90^{\circ} \mathrm{C}$, and the sulfuric acid aqueous solution $(80 \mathrm{wt} . \%, 8 \mathrm{~mL})$ was introduced into the mixture. The reaction continues for $10 \mathrm{~h}$ at $90^{\circ} \mathrm{C}$. Finally, the mixture was cooled to a yellowish diaphanous viscous liquid, and the Jeffamine-triazole derivatives (JD2000) were obtained. The reaction formula and structural formula of the JD2000 are shown in Figure 1.

(a)<smiles>CC(N)COC(C)(C)COCC(C)NCn1nnc2ccccc21</smiles>

(b)<smiles>CC(COCC(C)NC(C)Cn1nnc2ccccc21)NCn1nnc2ccccc21</smiles>

Figure 1. (a) The reaction formula. (b) The structural formula of the product.

\subsection{Pretreatment of the Friction Pair}

In practical use, different friction pairs often appear in different working conditions. Due to its high tensile strength and low cost, steel is used in buildings, infrastructure, tools, ships, trains, cars, machines, electrical appliances, and weapons. With the properties of low density, non-toxicity, easy recovery, electrical conductivity, and heat transfer, the recycling of aluminum alloys has been shown to provide major economic benefits and has been widely used in aerospace, automation, and advanced machinery. To meet the needs of different conditions and expand the usage of the products, 304 stainless steel and 6061 aluminum alloy substrates were selected as the lower stationary block in the friction pairs. Before the friction test, steel and aluminum plates were immersed in a mixture of petroleum ether (analytical pure, Sinopharm Chemical Reagent Co., Ltd., Shanghai, China) and ethanol (analytical pure, purity 99\%, Sinopharm Chemical Reagent Co., Ltd., Shanghai, China). Afterwards, ultrasonication was performed in a water bath for $15 \mathrm{~min}$ to remove the surface impurities and contaminants. The surface was then blow-dried using nitrogen gas flow. The resulting steel and aluminum plates were retained for tribological testing.

\subsection{Friction and Wear Tests}

A Bruker UMT-tribolab tester (Bruker, Billerica, MA, USA) was used to evaluate the tribological performance of the additive. The tests were performed in a ball-on-block configuration. Contact between the friction pairs was achieved by applying pressure to the upper running ball (8 mm in diameter, GCr15 steel, hardness of approximately 59-61 HRC) against the lower stationary block in the reciprocating mode. The variation in friction force and displacement with time during the test were controlled using a computer, and the entire process was recorded. The test was under a load of $7 \mathrm{~N}$ at a frequency of $4 \mathrm{~Hz}$ at room temperature $\left(25^{\circ} \mathrm{C}\right)$ and ambient humidity $(30.2 \%)$ for $30 \mathrm{~min}$. Distilled water and solutions with different concentrations of the JD2000 were adopted as the lubricants. All of the tests were repeated three times.

\subsection{Corrosion Tests}

The JB/T 9189-2016 method was applied to evaluate the anti-rust performance of the JD2000. In the experiment, cast iron scraps of the same quality were evenly spread on the 
filter paper in two culture dishes, and the same amount of water and additive solution were removed with a dropper to evenly wet the iron scraps. After the culture dish was covered, it was kept away from light and humidity for $2 \mathrm{~h}$ at room temperature. After the experiment, we removed the iron scraps, rinsed the filter paper with toluene, and dried it in the air. The number and area of rust spots on the filter paper were visually checked to determine the corrosion grade of the additive.

\subsection{Water Contact Angle Measurements}

The DSA30R interfacial rheometer (KRÜSS, Hamburg, Germany) was applied to measure the water contact angle of the additive on different metal surfaces. We first submerged the steel plates and aluminum plates used in the tribological test in pure water with or without $2 \mathrm{wt}$ \% JD2000 additive for half an hour at room temperature. The plates were rinsed with toluene and dried in the air, generating the plates for tests. The change of contact angle with time was recorded, and the adsorption rate of lubricant on metal surface was obtained.

\subsection{Adsorption Behavior Test of the JD2000 on Metal Surface}

Q-sense 401 quartz crystal microbalance with dispersion (QCM-D, Biolinscientific, Gothenburg, Sweden) was used to investigate the adsorption behavior of the JD2000 on the metal surface. Compared with iron wafers, which are prone to chemical reactions during the pre-cleaning process and may affect test results, gold wafers can avoid such problems. At the same time, related studies showed that the adsorption behaviors of samples on these two surfaces are consistent. Hence, we adopted the metallographic wafer as the adsorption surface for testing in this study.

During the process, the cleaned wafer was placed on the $\mathrm{O}$ ring of the QCM-D flow cell and connected to the device. Then, the dodecane solution flowed throughout it at a rate of $80 \mu \mathrm{L} / \mathrm{min}$. When the $\Delta \mathrm{F}$ and $\Delta \mathrm{D}$ curves were stable, we established a baseline and applied the $2 \mathrm{wt}$ \% JD2000 aqueous solution. After the absorption was stable, we waited another $30 \mathrm{~min}$ and removed the sample, which then had dodecane flow through it again for about $15 \mathrm{~min}$. At the end of the experiment, the instrument was cleaned with petroleum ether, ethanol, and deionized water. All the data were real-time recorded.

\subsection{Characterization of Product Structure and Investigation of Worn Surface}

To verify the product structure, the Fourier transform infrared (FTIR) spectra were collected using Paragon 1000 (PerkinElmer, Inc., Waltham, MA, USA) with the attenuated total reflection (ATR) attachment scanning from 4000 to $650 \mathrm{~cm}^{-1}$. Nuclear magnetic data were collected with a Bruker AVANCE III HD spectrometer (Bruker, Billerica, MA, USA) in $\mathrm{CDCl}_{3}$ with trimethylsilane as the reference. Measurements were performed with MALDI-TOF MS (Bruker autoflex III, Bruker, Billerica, MA, USA) equipped with a pulsed $\mathrm{N}_{2}$ laser $(337 \mathrm{~nm}$ ). An accelerating voltage of $20 \mathrm{kV}$ was used. The Malvenpanako (Viscotek GPC/SEC, Viscotek Corp, Houston, TX, USA) was used to measure the molecular weight distribution of the additive. The Contour GT (Bruker, Billerica, MA, USA) was used to investigate the morphology (WLI) of the worn surfaces and the wear degree. Prior to the study, the plates were cleaned in an ultrasonic bath with petroleum ether for $10 \mathrm{~min}$ and lightly mopped with a clean tissue. To analyze the chemical composition on the worn scars, the X-ray photoelectron spectroscopy (XPS) data were obtained from thermo scientific Escalab 250xi (ESCALAB250Xi, Thermo Fisher Scientific, Waltham, MA, USA) with Al K $\alpha$ radiation, and the vacuum degree of the analysis chamber was $8 \times 10^{-10} \mathrm{~Pa}$. Scanning electron microscopy (SEM) and energy-dispersive $X$-ray spectroscopy were conducted on AZtec X-MaxN 80 (Oxford, Abingdon, UK), and the Raman spectra were collected using Thermo DXR 2xi (Thermo Fisher Scientific, Waltham, MA, USA) in a range from 3500 to $50 \mathrm{~cm}^{-1}$ with a $532 \mathrm{~nm}$ laser source. 


\section{Results}

\subsection{Chemical Structures of the JD2000}

Figure 2a shows the FTIR spectra of the JD2000. Sharp peaks near $3030 \mathrm{~cm}^{-1}$ were observed in the FTIR spectra of the JD2000, which were assigned to the stretching vibration peak of the $\mathrm{C}-\mathrm{H}$ bond of the benzene ring. The peaks near $1600 \mathrm{~cm}^{-1}$ were due to the stretching vibration of the $-\mathrm{CH}_{3}$ bond. The stretching vibration peak near $1100 \mathrm{~cm}^{-1}$ was assigned to the $\mathrm{N}=\mathrm{N}$ double bond. The strongest peak at $1170 \mathrm{~cm}^{-1}$ was the stretching vibration peak of the $\mathrm{C}-\mathrm{O}-\mathrm{C}$ single bond, proving the existence of the ether bond appearing in the spectra of the JD2000. The FTIR results demonstrate that the JD2000 was successfully produced from benzotriazole and formaldehyde. Figure $2 b$ shows the ${ }^{1} \mathrm{H}$ NMR spectra of the JD2000. The chemical shifts of 7.79 and $7.34 \mathrm{ppm}$ represent the hydrogen atoms in the benzene ring, the chemical shifts of $4.45 \mathrm{ppm}$ represent the signal of the active methylene group, and a new peak was produced. The peaks of 1.0 and $3.86 \mathrm{ppm}$ represent the methyl and methylene signals on the polyether chain. The nuclear magnetic resonance data show that the product contained benzotriazole and polyether chains, and the target product, JD2000, was successfully obtained.

(a)

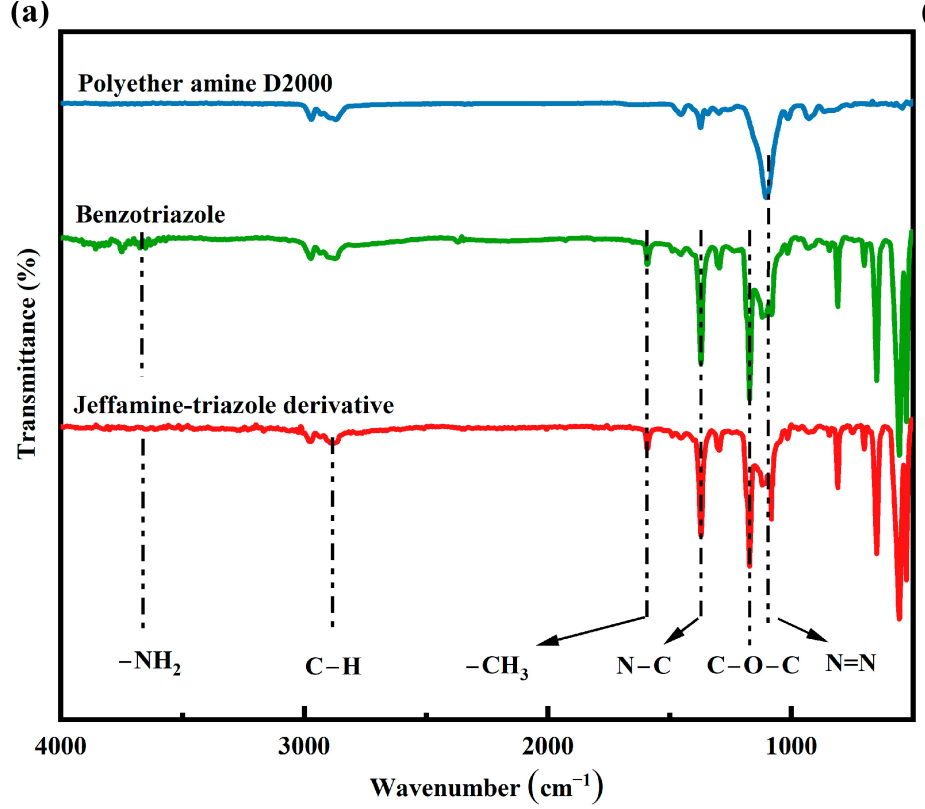

(b)

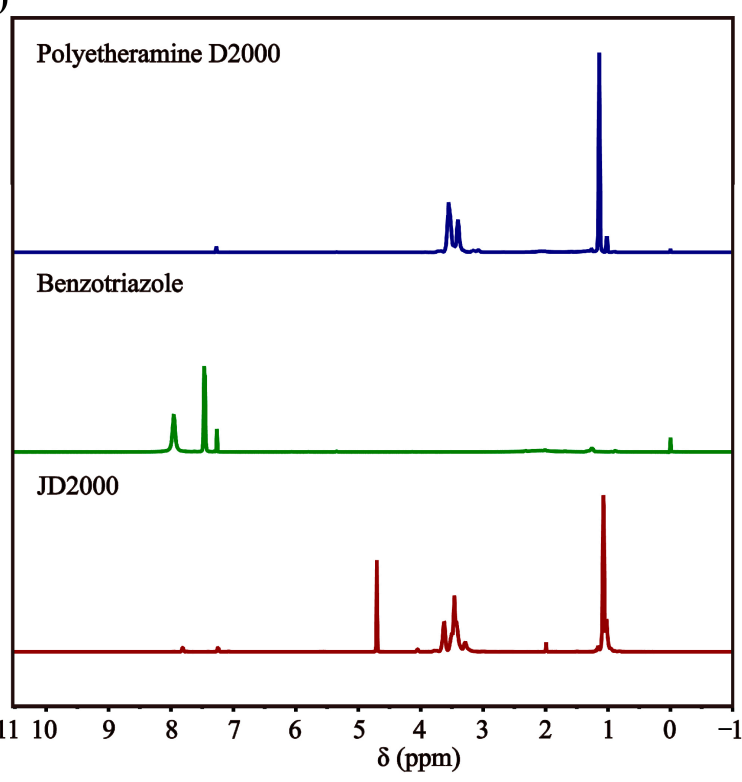

Figure 2. The (a) FTIR and (b) ${ }^{1}$ H NMR spectra of the JD2000.

The structure of the JD2000 product was analyzed using mass spectrometry, as shown in Figure 3. The peak at $2334 \mathrm{~m} / \mathrm{z}$ is the derivative of Jeffamine-triazole at $\mathbf{n}=34$. The disparity of $m / z$ between the adjacent peaks is approximately 58 , which represents the difference of a $-\mathrm{C}_{3} \mathrm{H}_{6} \mathrm{O}$ structure. GPC results are shown in the inset's table. The number average molecular weight $(\mathrm{Mn})$ is 1055 , and the weight average molecular weight $(\mathrm{Mw})$ is 2234. The degree of dispersion $(\mathrm{Mw} / \mathrm{Mn})$ is 2.117. It can be seen that the molecular weight of the JD2000 is concentrated around 2234, and the main degree of polymerization is 34 . The results show that the synthesized product had a polyether chain structure and was a mixture of derivatives with different degrees of polymerization. 


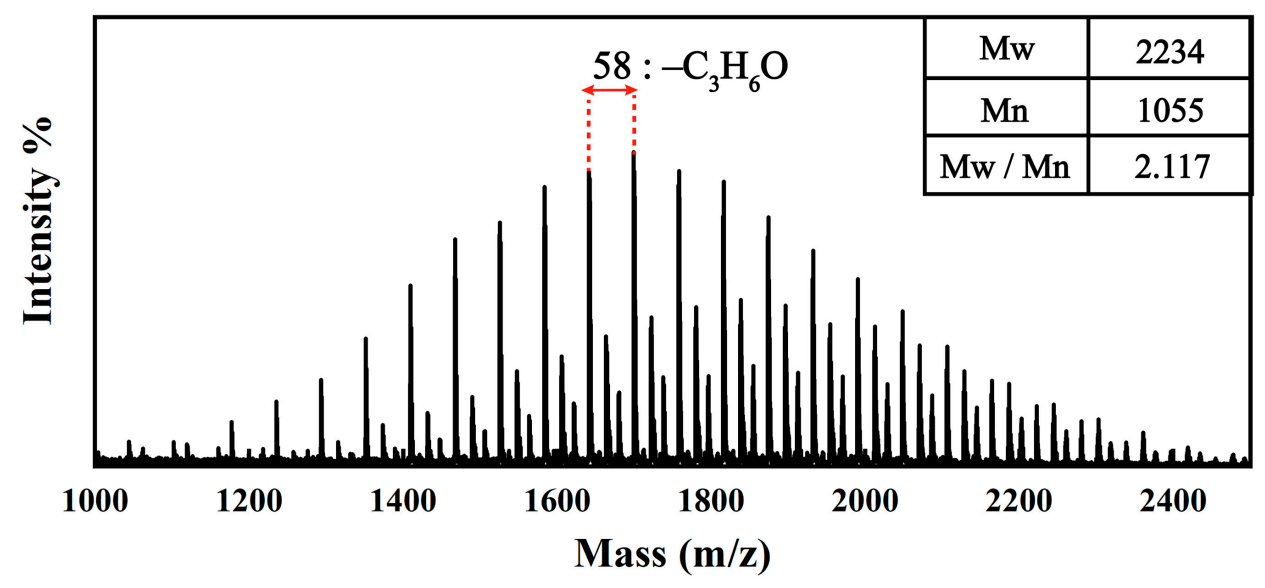

Figure 3. The MS spectra of the JD2000.

\subsection{Configuration and Stability Test of the JD2000 Water-Based System}

Due to the inclusion of various ions and impurities in tap water, which may affect the tribological behavior of an aqueous solution, the water used in this experiment was distilled water. The JD2000 was introduced into the distilled water and ultrasonically dispersed in a water bath for $30 \mathrm{~s}$ to obtain a uniformly dispersed water solution. In this experiment, the JD2000 aqueous solutions with mass fractions of $0.25,0.5,1,2$, and $4 \mathrm{wt}$.\% were prepared. As shown in Figure 4a, the aqueous solutions of the JD2000 with different concentrations were all clear and diaphanous, and they gradually became pale yellow with increasing concentration. To observe their solubility stabilities in water, the JD2000 aqueous solutions with different concentrations were left for one month. The results are shown in Figure 4b. The JD2000 aqueous solutions with different concentrations remained clear and diaphanous, and no precipitation phenomenon occurred. The results show that the JD2000 stably dissolved in water, and the JD2000 aqueous solutions with different concentrations were obtained.
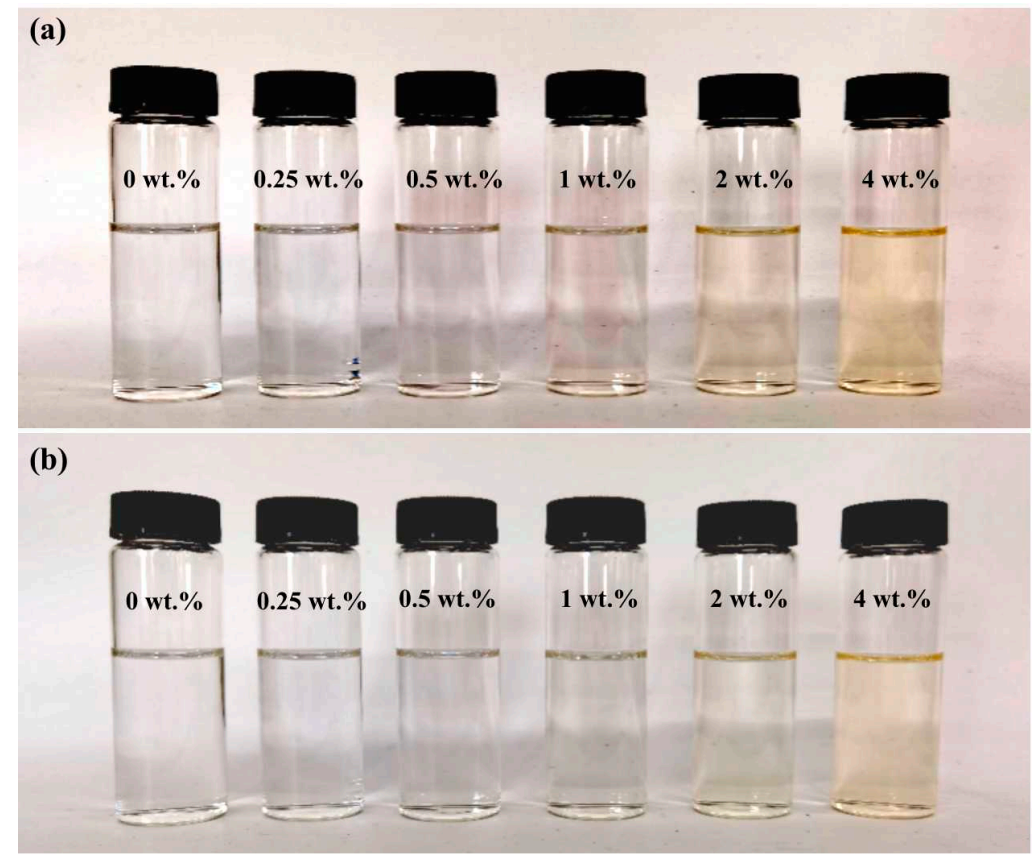

Figure 4. The JD2000 aqueous solutions with different concentrations with standing time of: (a) one day; and (b) one month. 


\subsection{Friction Reduction and Anti-Wear Properties of the Steel Plates}

To test the anti-friction property of water with JD2000 concentrations ranging from 0 to $4 \mathrm{wt} . \%$ on the steel plates, the tribological test was conducted on the UMT-tribolab tester. The test results of the average friction coefficients (COF) of the different concentrations of the JD2000 aqueous solutions are shown in Figure 5a. It can be seen that the COF of the distilled water was 0.481 . After adding the lubricant, the COF decreased obviously with increasing amounts of the additive. When the JD2000 concentration was $2 \mathrm{wt} . \%$, the COF was 0.185 compared with the distilled water, and the anti-friction property was improved by $61.4 \%$. When the concentration further increased to $4 \mathrm{wt} . \%$, the COF of the system was 0.182 , and the anti-friction property was improved by $62.1 \%$. The COF reduction was not obvious compared with the case of $2 \mathrm{wt} . \%$. The results show that the lubrication effect of the JD2000 was sensitive to its concentration. The low concentration JD2000 did not form tribofilms. In this study, a JD2000 concentration of $2 \mathrm{wt} . \%$ was applicable for the JD2000 to exert its lubrication ability.
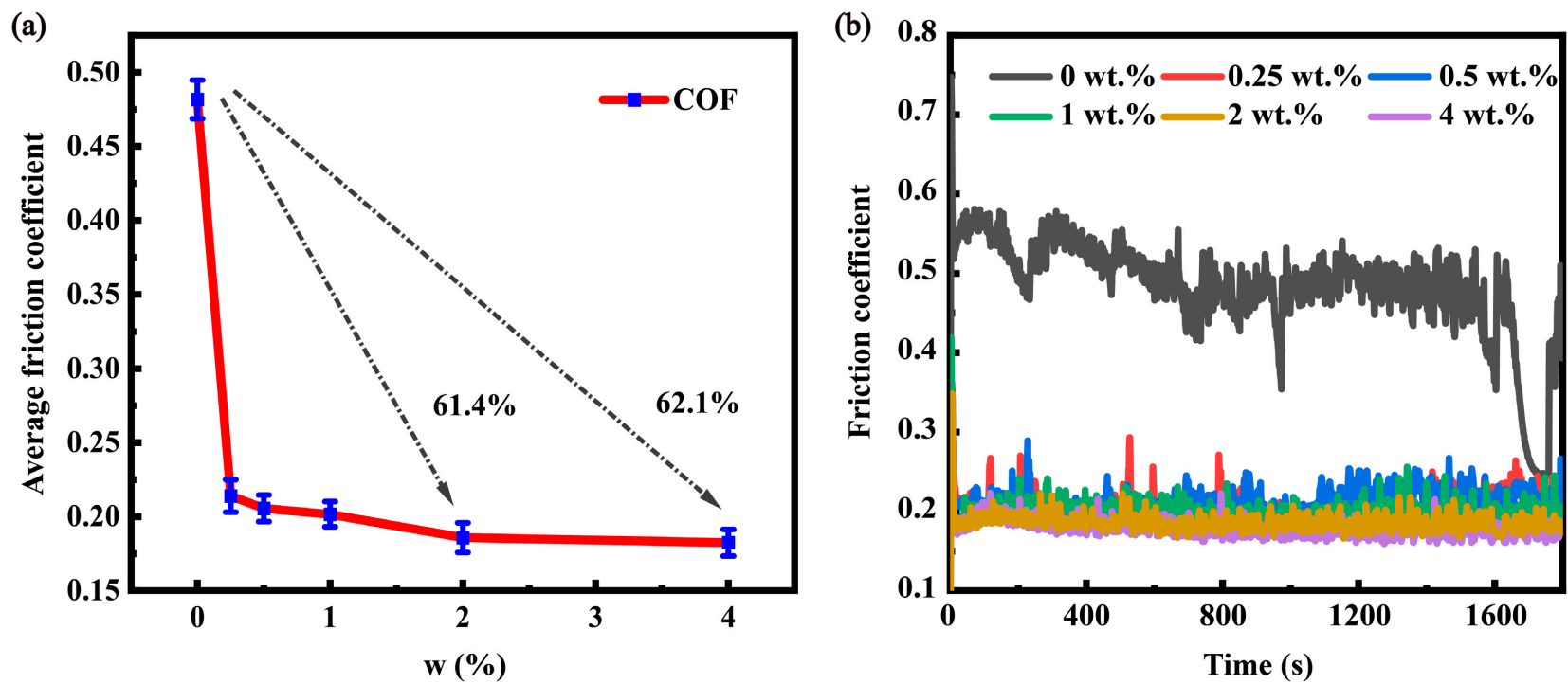

Figure 5. The (a) COF and (b) friction coefficient curves of frequency ramp-up reciprocation with the JD2000 concentrations ranging $0-4 \mathrm{wt} . \%$ on the steel plates.

To further analyze the variation in the friction coefficient during the friction process, the real-time friction coefficient curves of the steel plates lubricated using the JD2000 aqueous solutions are shown in Figure $5 \mathrm{~b}$. It can be seen that the friction coefficient of the distilled water was very unstable and always fluctuated at a higher value. When the JD2000 was added, the friction coefficient and the fluctuation of the friction curve decreased. The average friction coefficient decreased with increasing amounts of the additions, and the stability of the curve increased with increasing concentrations.

The wear conditions of the steel plates lubricated using the JD2000 aqueous solutions with different concentrations are shown in Figure 6. It can be seen that the wear scar width and depth of the distilled water were $0.36 \mathrm{~mm}$ and $4.03 \mu \mathrm{m}$, respectively, being the smallest of all the samples. With an increase of the JD2000 concentrations, the width and depth of the wear mark increased gradually. The results show that the water-based lubricant JD2000 had no anti-wear property on the 304 steel plate. 

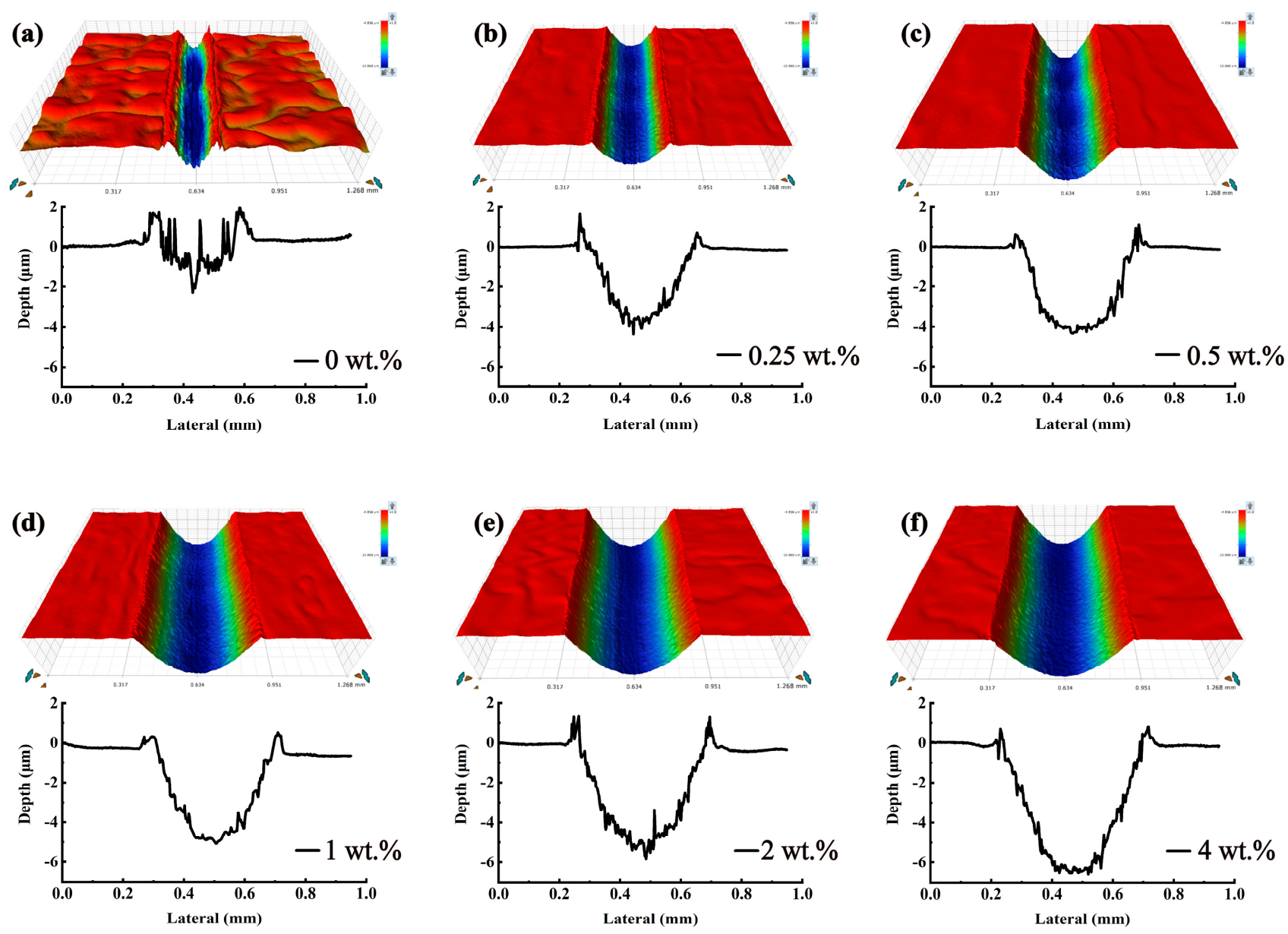

Figure 6. The surface curves and WLI morphologies on the worn disks lubricated using the JD2000 water aqueous solutions with different concentrations: (a) 0 wt.\%, (b) 0.25 wt.\%, (c) $0.5 \mathrm{wt} . \%$, (d) 1 wt. $\%$, (e) 2 wt. $\%$ and (f) 4 wt.\%.

\subsection{Friction Reduction and Anti-Wear Properties of the Aluminum Plates}

Figure 7a shows the COF of the different concentrations of the JD2000 aqueous solutions. The COF of distilled water was 0.361 . In comparison, with the addition of 0.25 , $0.5,1,2$, and 4 wt. $\%$ JD2000, the COF decreased to $0.180,0.181,0.145,0.129$, and 0.205, respectively. It can be seen that, with the JD2000 concentration of $2 \mathrm{wt} . \%$, the anti-friction property was improved by $64 \%$ compared with the distilled water. However, when the concentration was further increased to $4 \mathrm{wt} . \%$, the COF of the system increased. The results show that the low JD2000 concentrations were unable to form tribofilms, while a high additive concentration caused an excess of long chains in the water that generated the aggregation complication and increased friction. Therefore, in this study, the JD2000 with concentration of $2 \mathrm{wt} . \%$ was applicable for the JD2000 to exert its lubrication ability.

To further analyze the variation in the friction coefficient during the friction process, the real-time friction coefficient curves lubricated using the JD2000 aqueous solutions on the surface of the steel plates are shown in Figure $7 \mathrm{~b}$. It can be seen that the friction coefficient of the distilled water was very unstable and always fluctuated at a higher value. When a small amount of the JD2000 (0.25 and $0.5 \mathrm{wt} . \%)$ was introduced into the distilled water, the fluctuation and the friction coefficient of the aqueous solutions decreased. This can be attributed to the aluminum plate being less rigid than the steel balls. During the friction process, the rough surface directly contacted and sheared mutually under the squeezing action, making the soft aluminum plate easily produce metal debris. This led to abrasive and adhesive wear, and the friction coefficient increased rapidly. Then, a portion of the debris was extruded from the friction orbit and entered the surrounding aqueous solution system, and the friction coefficient decreased accordingly. This process was 
repeated throughout the friction testing process, making the friction curve of the distilled water and a lower concentration of the JD2000 aqueous solutions change periodically. When the concentrations of the JD2000 increased to 1 and $2 \mathrm{wt} . \%$, it was observed that the friction curve had no obvious fluctuation and remained at the lowest point. The friction coefficient of the $2 \mathrm{wt} . \%$ JD2000 aqueous solutions was very stable and stayed at the lowest value, showing that the JD2000 had the best anti-friction property at $2 \mathrm{wt} . \%$. When the concentration of the JD2000 was increased to $4 \mathrm{wt} . \%$, the friction curve resumed its periodic fluctuation, and the friction coefficient also increased. It is speculated that this was because the appropriate concentration of the JD2000 could well cover the surface of the aluminum plates, forming a stable friction film and preventing the direct contact of the rough surface. When the amount of additive continued to increase, the thickness of the lubrication film increased, which tended to form an agglomeration of molecular chains. This led to an increase in the friction coefficient.
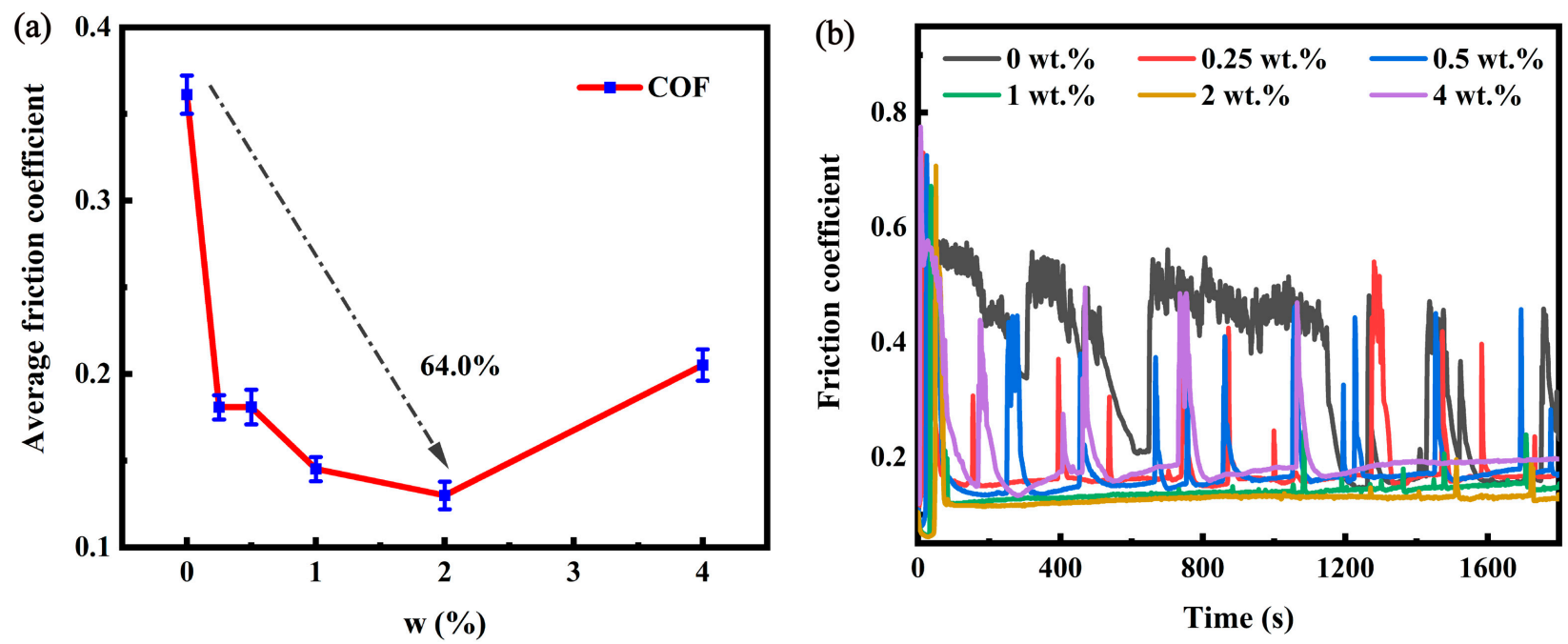

Figure 7. The (a) COF and (b) friction coefficient curves of frequency ramp-up reciprocation with the JD2000 concentrations ranging $0-4 \mathrm{wt} . \%$ on the aluminum plates.

The 3D topography and the profile depth curve of the wear marks on the surface of the aluminum plates after the friction test are shown in Figure 8. It can be clearly observed that the surface of the aluminum plates was heavily worn after the distilled water friction, with a width of approximately $3.1 \mathrm{~mm}$ and a depth of $92.5 \mu \mathrm{m}$. After the addition of the JD2000 lubricant, the wear amount decreased significantly, and the width and depth of wear marks decreased gradually with an increase in the JD2000 addition. With the addition of the $2 \mathrm{wt} . \%$ JD2000 in water, the width and depth of the abrasion mark were $0.7 \mathrm{~mm}$ and $2.3 \mu \mathrm{m}$, which were reduced by $77.4 \%$ and $97.5 \%$, respectively, compared with that of the distilled water, greatly improving the friction and wear phenomenon of the water system. With this result combined with the real-time friction coefficient curves, it can be concluded that the $2 \mathrm{wt} . \%$ JD2000 water dispersion had the best comprehensive lubrication performance of all the samples.

The wear volume at the wear mark on the aluminum plates with different concentrations of the JD2000 water solutions after the tribological experiment were calculated. The results are as shown in Figure 9. With an increase in the concentration of the additive, the wear volume gradually decreased. It can be seen that the wear volume of the distilled water was $0.034 \mathrm{~mm}^{2}$. With the addition of $2 \mathrm{wt} . \%$ JD2000 in the water, the wear volume of the abrasion mark was $0.004 \mathrm{~mm}^{2}$, which was reduced by $88.2 \%$ compared with that of the distilled water. Therefore, the JD2000 had an excellent anti-wear property on the aluminum plate. 

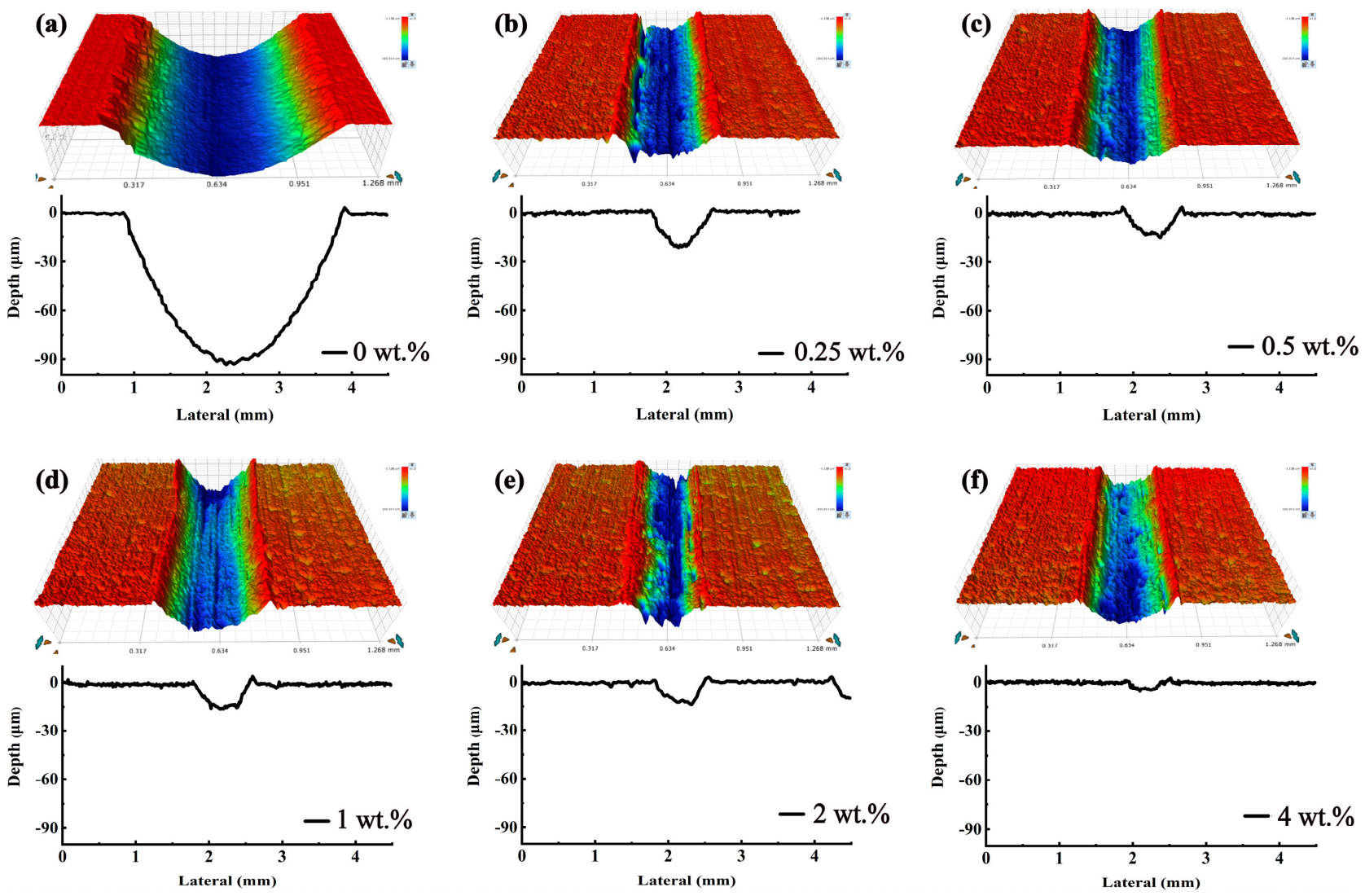

Figure 8. The surface curves and WLI morphologies on worn disks lubricated by the JD2000 water aqueous solutions with different concentrations: (a) 0 wt. \%, (b) 0.25 wt.\%, (c) 0.5 wt. \%, (d) 1 wt. \%, (e) 2 wt.\% and (f) 4 wt.\%.

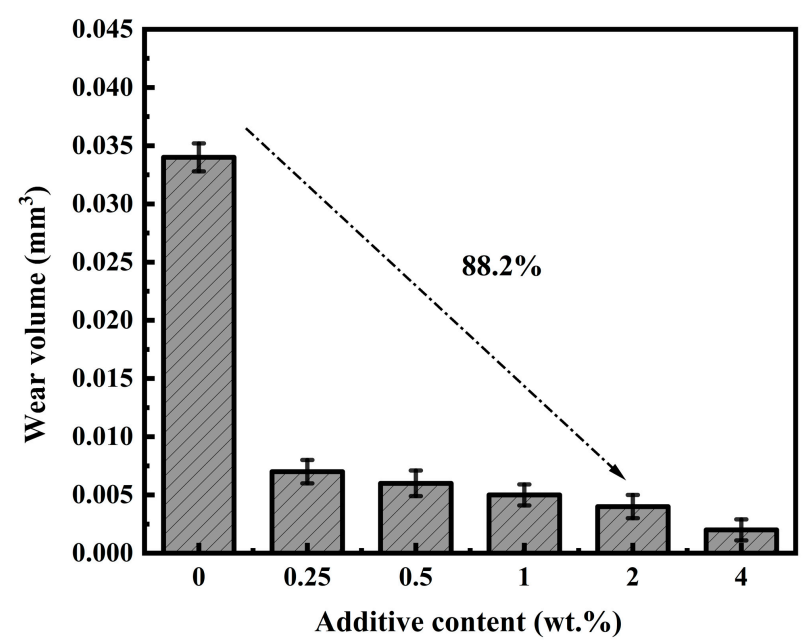

Figure 9. The wear volume of the water scar lubricated by the JD2000 aqueous solutions with different concentrations on the aluminum plates measured using the UMT tribometer.

\subsection{Anti-Corrosion and Anti-Rust Property}

The results of corrosion tests are shown in Figure 10. Corrosion grades were assigned according to the JB/T 9189-2016. It can be observed that, when the distilled water was used as anti-rust solution, the surface rust area of filter paper was more than $5 \%$, which belongs to severe corrosion. When the $2 \mathrm{wt} . \%$ JD2000 aqueous solution was used as antirust solution, the surface rust area of filter paper was between $1 \%$ and $5 \%$, belonging to moderate corrosion. Comparing the area of rust spots produced by the two kinds of anti-rust solutions, it can be seen that the addition of the JD2000 can reduce the corrosion degree by about $75.5 \%$, which has significant anti-rust performance. 
(a)

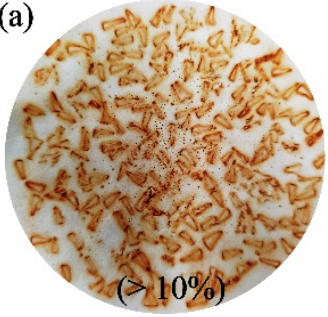

(b)

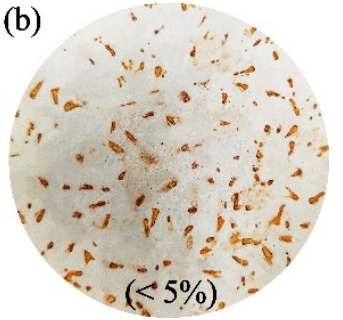

Figure 10. The results of corrosion tests with (a) distilled water and (b) 2 wt.\% JD2000 as antirust agent.

\subsection{Lubrication Mechanisms}

\subsubsection{Analysis of Water Contact Angle Measurements Results}

The ability to adsorb onto a metal surface is essential to the effectiveness of additives. Water contact angle measurements were performed to evaluate the adsorption behavior of polar molecules on the metal surface (Figure 11a-d). The results show that the contact angles of the surfaces decreased with the addition of the JD2000 additive, which contained multiple surface active nitrogen atoms [9]. This is because the nitrogen atoms can combine with the metal surface elements, forming a firm adsorption layer, which can still exist on the metal surface after rinsing. In the contact angle test, the hydrophilic group of the JD2000 can combine with water, and the water spreads out on the metal surface, resulting in the reduction of contact angles. The adsorption curve (Figure 11e) shows that the JD2000 lubricant spreads faster on the metal surface and forms a film rapidly (as illustrated in the inset), which verifies the conjecture of adsorption film.

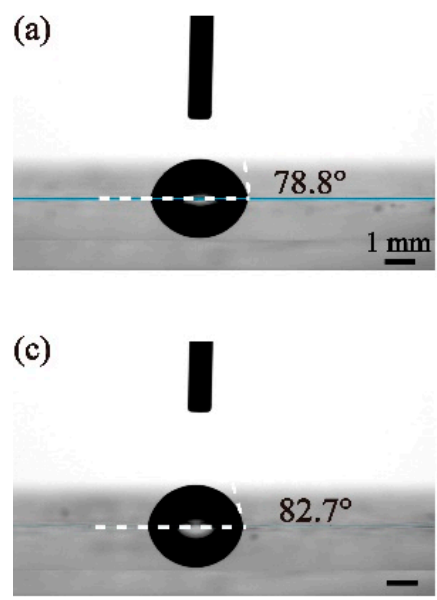

(b)

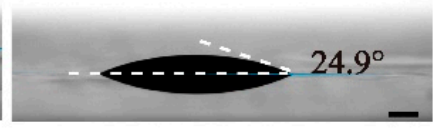

(d)

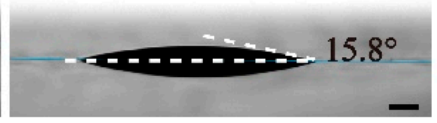

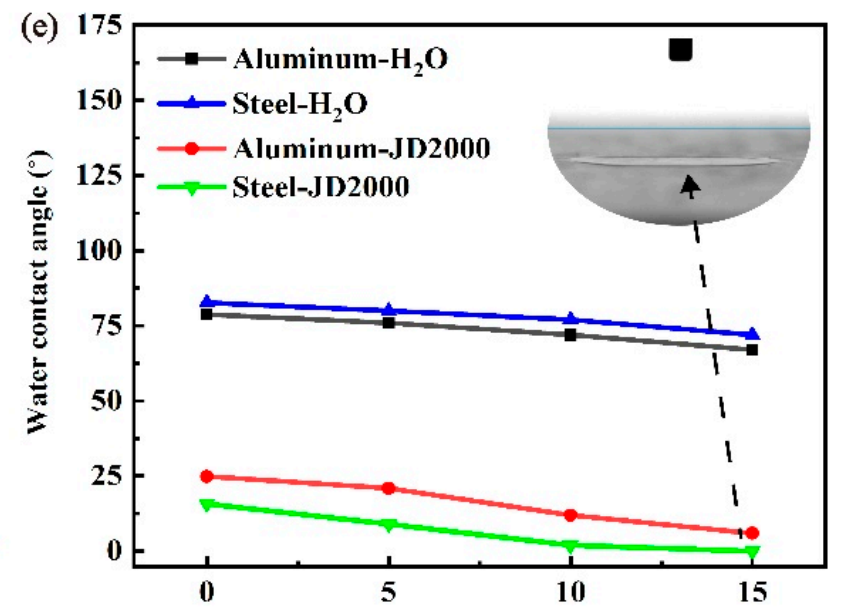

Figure 11. Aqueous contact angle goniometry dip-coated with: (a) distilled water on the steel plates; (b) 2 wt.\% JD2000 on the steel plates; (c) distilled water on the aluminum plates; and (d) $2 \mathrm{wt} . \%$ JD2000 on the aluminum plates. (e) The adsorption curves.

\subsubsection{Analysis of Adsorption Behavior Results}

The change in frequency $(\Delta \mathrm{f})$ depends on the quantity of the molecules adsorbed on the surface of the wafer. It can be seen that, with the adsorption of the JD2000 on the surface, $\Delta \mathrm{f}$ of the wafer surface increased significantly (Figure 12a), indicating that the adsorption rate was greater than the desorption rate; the curve was stable after 15,000 s, indicating that the absorption/desorption rate had reached equilibrium at this time. After the surface was rinsed with dodecane, the curve had no obvious change, implying that the adsorption of the JD2000 on the metal surface was highly stable. The change in energy dissipation factor $(\Delta \mathrm{D})$ reflects the internal viscoelasticity and structural changes of the substance. When $\Delta \mathrm{D}<10^{-6}$, it means that a rigid film is formed on the surface, and when $\Delta \mathrm{D}>10^{-6}$, a viscoelastic film is formed on the surface. As shown in Figure 12b, after 
adsorption on the surface, the elastic modulus of the JD2000 increased and far exceeded $10^{-6}$, showing that the JD2000 formed a typical viscoelastic film on the surface, which kept the film intact without fracture under the action of experimental load and provided long-term lubrication protection for the metal surface.
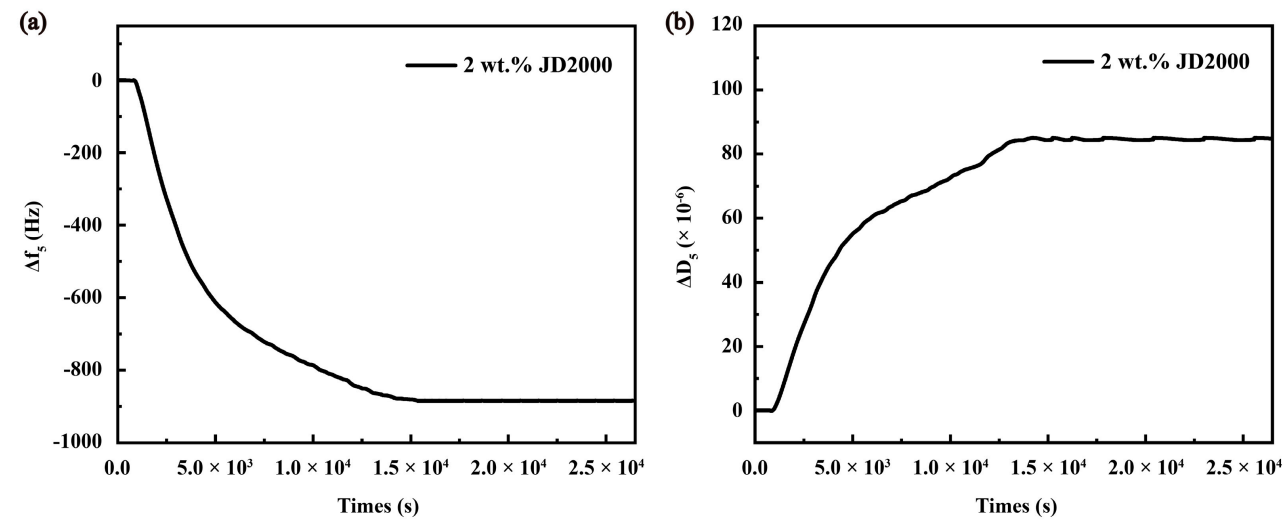

Figure 12. (a) Frequency variation curve and (b) energy dissipation factor variation curve of the 2 wt.\% JD2000 aqueous solution on the metal surface.

\subsubsection{Analysis of the Worn Surfaces of Steel Plates}

To further investigate the wear surfaces of the aluminum plates, the overall SEM images were recorded, as shown in Figure 13. Figure $13 a_{1}-a_{3}$ shows the surface morphology of the wear marks with different water lubrication under different magnifications. Figure $13 b_{1}-b_{3}$ shows the surface morphologies of the wear marks under different magnifications with the $2 \mathrm{wt} . \%$ JD2000 lubrication. The SEM of the wear surface with a higher magnification is shown on the left side to give more details of the wear surface. When the SEM images of the wear surfaces were viewed at the same magnification, it was clearly shown that the JD2000 corresponded to a smaller wear volume compared with the distilled water. It can be seen that the surfaces of the steel plates were severely worn under the distilled water lubrication, with obvious grooves and bumps. In addition, tiny metal fragments were distributed on the wear track. The surfaces were very coarse because of the experimental load. Direct contact between the surfaces of the friction pairs resulted in mutual shearing, and the friction between the rough surfaces made the surface particles peel off. This in turn led to the wear of the abrasive particles, resulting in a higher friction coefficient. With the addition of the additive, the surface quality was improved, and smooth surfaces with no metal debris, basically no grooves and bumps, and only slight scratches were obtained. In addition, the marks of the tribofilms filling can be observed. This could be attributed to the better adsorption of the active elements in the JD2000 on the surfaces, which formed a sheared film during the friction process and avoided direct contact between the metal surfaces of the friction pair.

To analyze the formation of the friction film on the steel surface under the $2 \mathrm{wt} . \%$ JD2000 lubrication condition, the MS of the JD2000 (Figure 4) and the friction-tested steel plates (Figure 14) were compared. When the $m / z$ values appeared near 567 and 854, it was speculated that this molecule was a JD2000 long chain that lost $\mathrm{C}_{6} \mathrm{H}_{4} \mathrm{~N}_{3} \mathrm{CH}_{2} \mathrm{NH}-$ and $\mathrm{CH}_{3}-$, and its degree of polymerization was 7 and 12 , respectively. When the $m / z$ value appeared near 642 , the corresponding molecule was the additive long chain with a lost $\mathrm{C}_{6} \mathrm{H}_{4} \mathrm{~N}_{3} \mathrm{CH}_{2} \mathrm{NH}$ - structure, and the degree of polymerization was 8 . The results show that the chemical bonds of the JD2000 molecular long chain broke and formed long chains with different molecular weights. These would cover the worn surface and further participate in the formation of the lubricating film, filling the wear marks. Hence, during the friction process, they would play a protective role in preventing metal debris and more serious wear. 

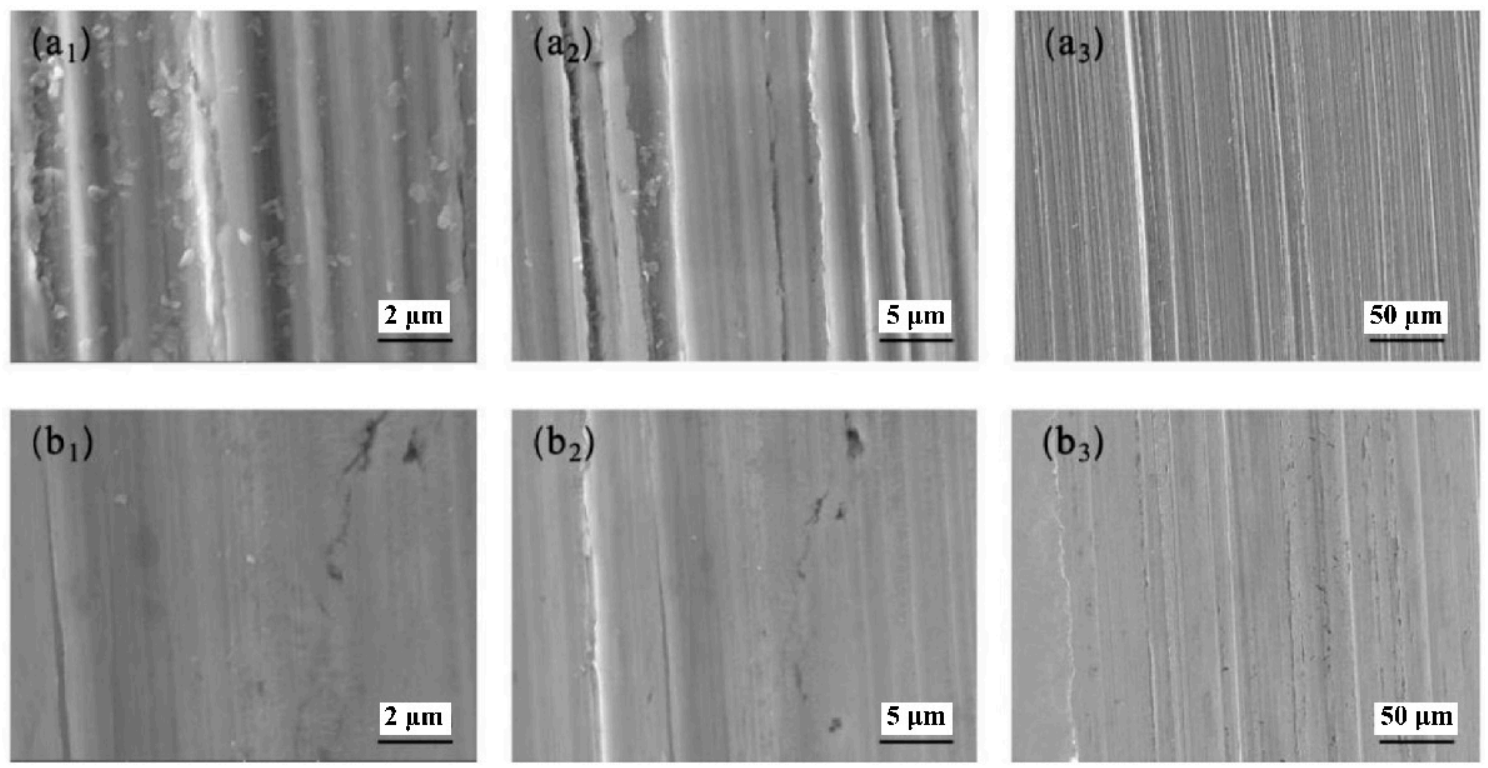

Figure 13. SEM images of the wear scar on the steel surface with: $\left(\mathbf{a}_{1}-\mathbf{a}_{3}\right)$ the distilled water; and $\left(\mathbf{b}_{1}-\mathbf{b}_{3}\right)$ the 2 wt.\% JD2000 aqueous solution.

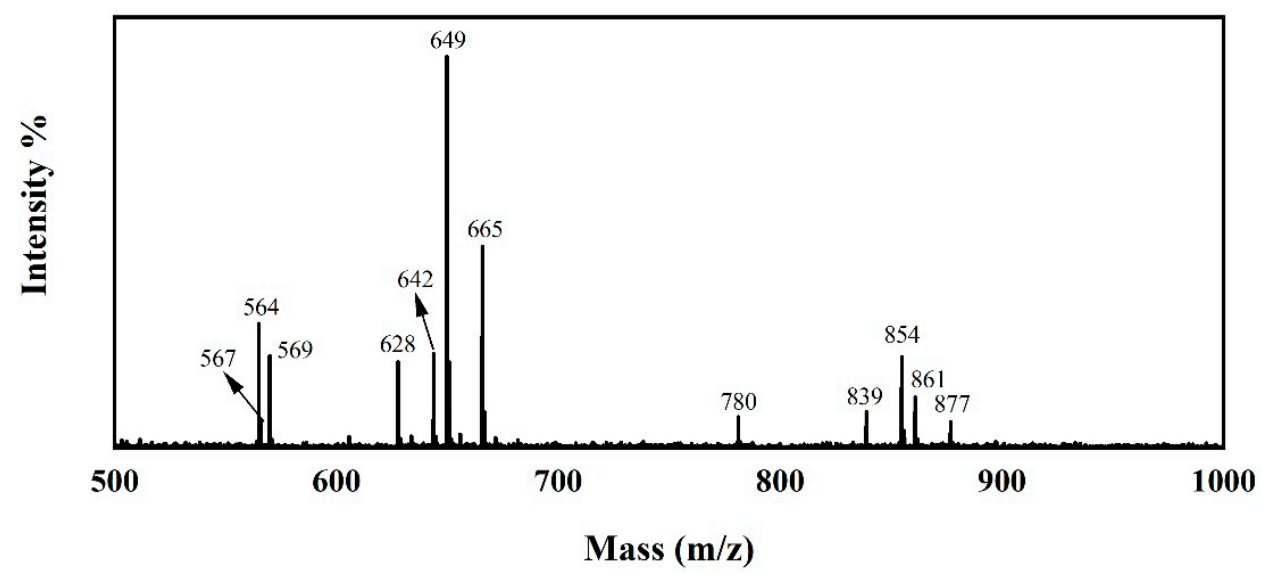

Figure 14. The MS spectra of the friction-tested steel plates lubricated by the $2 \mathrm{wt} . \%$ JD2000 aqueous solution.

The different element contents of the wear marks were obtained using EDS, as shown in Table 1. It can be observed that, when the distilled water was used as the lubricant, the most abundant element in the wear marks was $\mathrm{Fe}$, which came from the metal material of the friction pair and the wear debris produced during the friction process. $\mathrm{C}, \mathrm{Si}, \mathrm{Cr}, \mathrm{Ni}$, and Mn came from the inner material of the friction pair. When the JD2000 was introduced into the water, the worn surface containing $\mathrm{N}$ and O elements was derived from the JD2000, showing that the long chain JD2000 passed through the reactive elements and reacted with the metal surface. They then adhered to the surface stably and formed the protective film. In addition, the Mn element was only produced during the process of water friction, while its existence was not detected under the JD2000 lubrication. This indicated that the friction pair under water lubrication was seriously worn, and the wear was reduced after the addition of the JD2000.

Table 1. Element contents of the friction-tested steel plate.

\begin{tabular}{ccccccccc}
\hline Statistics (wt.\%) & $\mathbf{C}$ & $\mathbf{N}$ & $\mathbf{O}$ & $\mathbf{S i}$ & $\mathbf{C r}$ & $\mathbf{N i}$ & $\mathbf{M n}$ & $\mathbf{F e}$ \\
\hline worn surfaces under distilled water & 1.08 & 0 & 0 & 0.23 & 16.62 & 8.74 & 1.14 & 72.19 \\
worn surfaces under 2 wt.\% JD2000 aqueous solution & 1.7 & 7.64 & 3.89 & 0.58 & 17.16 & 6.36 & 0 & 62.67 \\
\hline
\end{tabular}


To further investigate the chemical composition of the tribofilms and illustrate the changes in the chemical states of the several typical elements on the worn surfaces, the composition of the wear marks on the steel plate after the friction test was analyzed using XPS. Figure 15 shows the high-resolution XPS spectra of C1s, O1s, Fe2p, and N1s. All of the XPS spectra were fitted using the Lorentzian-Gaussian method. The C1s spectra of the surface have a weak peak at $285.1 \mathrm{eV}$, which represents the $\mathrm{C}-\mathrm{O}$ chemical bond. There are two new peaks in the C1s spectra of the lubricating film formed by the JD2000, and the peaks at 288.5 and $286.1 \mathrm{eV}$ represent the $\mathrm{C}=\mathrm{O}$ and $\mathrm{C}-\mathrm{C}$ bonds of the lubricating film, respectively. These results indicate that the hydrocarbon compounds were absorbed tribo-physically on the worn surface. The peak of O1s at $531.0 \mathrm{eV}$ came from the $\mathrm{SiO}_{2}$, and the additive-containing lubricant also contained $\mathrm{NiO}$ bonds in the friction film formed during friction. The peak of the Fe2p spectra at $708.3 \mathrm{eV}$ corresponds to the binding energy of FeOOH. In addition, the binding energy peak at 705.7 and $718.8 \mathrm{eV}$ correspond to Fe2p3 and Fe2p1, respectively, while the new signal peak at $76.5 \mathrm{eV}$ is assigned to the $\mathrm{Fe}_{2} \mathrm{O}_{3}$, which was one of the components of the surface friction film. The spectra results of the $\mathrm{N}$ elements show that the active nitrogen elements in the additive also adsorbed on the surface of the steel plate, producing the binding energy peak of the $\mathrm{N}-\mathrm{O}$ bond at $399.3 \mathrm{eV}$. This made the long chain in the JD2000 bind tightly to the surface of the steel plate during the friction process, and thus it played a protective role to prevent direct contact between the metal friction pairs.
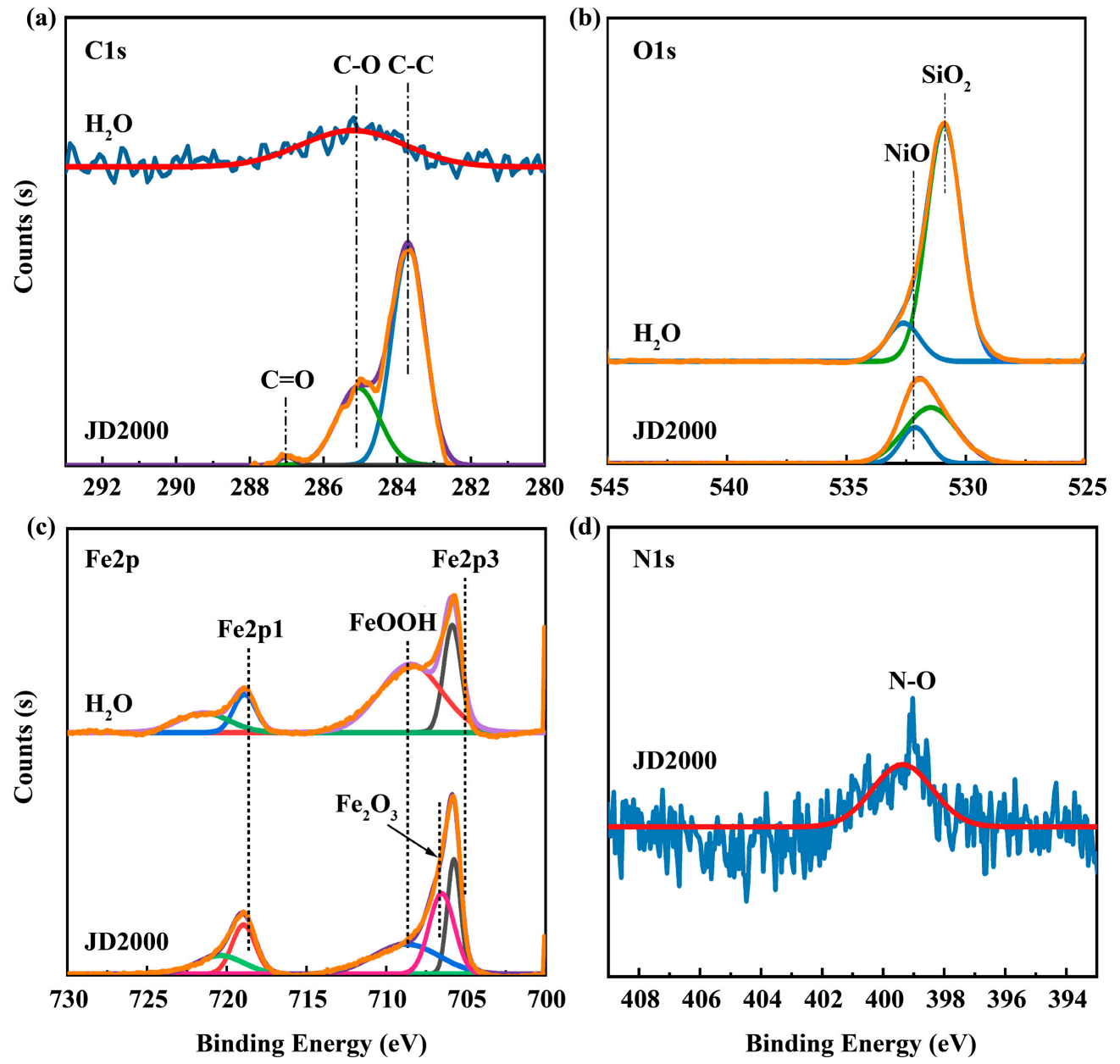

Figure 15. The XPS spectra of (a) C1s, (b) O1s, (c) Fe2p and (d) N1s on the wear scar of the steel ball lubricated using the $2 \mathrm{wt}$.\% JD2000 aqueous solution as measured using the UMT tribometer. 


\subsubsection{Analysis of the Worn Surfaces of Aluminum Plates}

To further investigate the wear surfaces of aluminum plates, the SEM images of the surface wear of the aluminum plates obtained by lubrication with distilled water and the $2 \mathrm{wt} . \%$ JD2000 were compared under the same test conditions. Figure $16 \mathrm{a}_{1}-\mathrm{a}_{3}$ shows the surface morphologies of the wear marks with the water lubrication under different magnifications. It can be seen that, under the distilled water lubrication, the surface of the aluminum plates was severely worn, and there were a large amount of wear debris and obvious cutting pits in the wear track. The surface was very rough, showing that the direct contact of the rough friction pairs caused surface particles to peel off and contribute a large amount of metal debris. This led to the deep and wide cutting pits. Figure $16 b_{1}-b_{3}$ shows the wear marks of the $2 \mathrm{wt}$.\% JD2000 lubrication under different magnifications. After adding the additive, the surface of the wear marks was smooth, with no obvious metal debris particles and grooves. However, it can be observed that the surface of the aluminum plates was covered with a thin layer of film, and the spalling lubricating film fragments can be clearly seen at a large multiple. This indicated that the JD2000 reacted with the metal surface during the friction process and produced the protected film. The fragments were produced when the chemical film was sheared during the friction process, which filled in the abrasion mark, avoided direct contact with the metal surface, and played an obvious lubrication role.
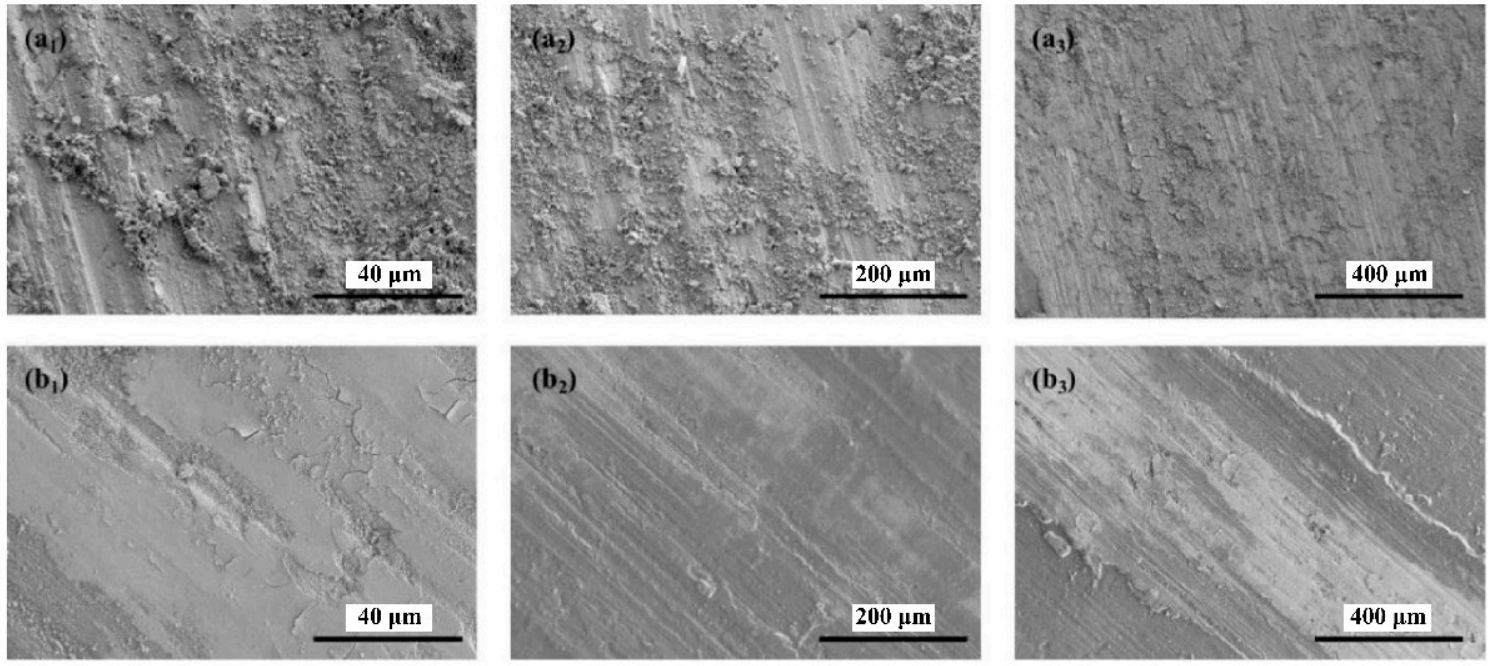

Figure 16. The SEM images of the wear scar on the aluminum plates with: $\left(\mathbf{a}_{\mathbf{1}}-\mathbf{a}_{3}\right)$ the distilled water; and $\left(\mathbf{b}_{\mathbf{1}}-\mathbf{b}_{\mathbf{3}}\right)$ the 2 wt.\% JD2000 aqueous solution.

Figure 17 shows the MS of the friction-tested aluminum plates under the $2 \mathrm{wt} . \%$ JD2000 lubrication condition. It can be seen that the polymer can be detected at the wear place of the aluminum plates after lubrication with the JD2000, and the results are very similar to those of the steel plates. When the $\mathrm{m} / \mathrm{z}$ values were near 569 and 855 , it was speculated that this molecule was a JD2000 long chain that lost $\mathrm{C}_{6} \mathrm{H}_{4} \mathrm{~N}_{3} \mathrm{CH}_{2} \mathrm{NH}$ - and $\mathrm{CH}_{3-}$, and its degrees of polymerization were 7 and 12 . When the $m / z$ value was near 649 , the corresponding molecule was the additive long chain with the lost $\mathrm{C}_{6} \mathrm{H}_{4} \mathrm{~N}_{3} \mathrm{CH}_{2} \mathrm{NH}-$ structure, and the degree of polymerization was 8 . The results show that the chain of the JD2000 molecule broke and formed chains with different molecular weights during the friction process. This then filled in the wear track to prevent direct contact with the uneven metal surface. 


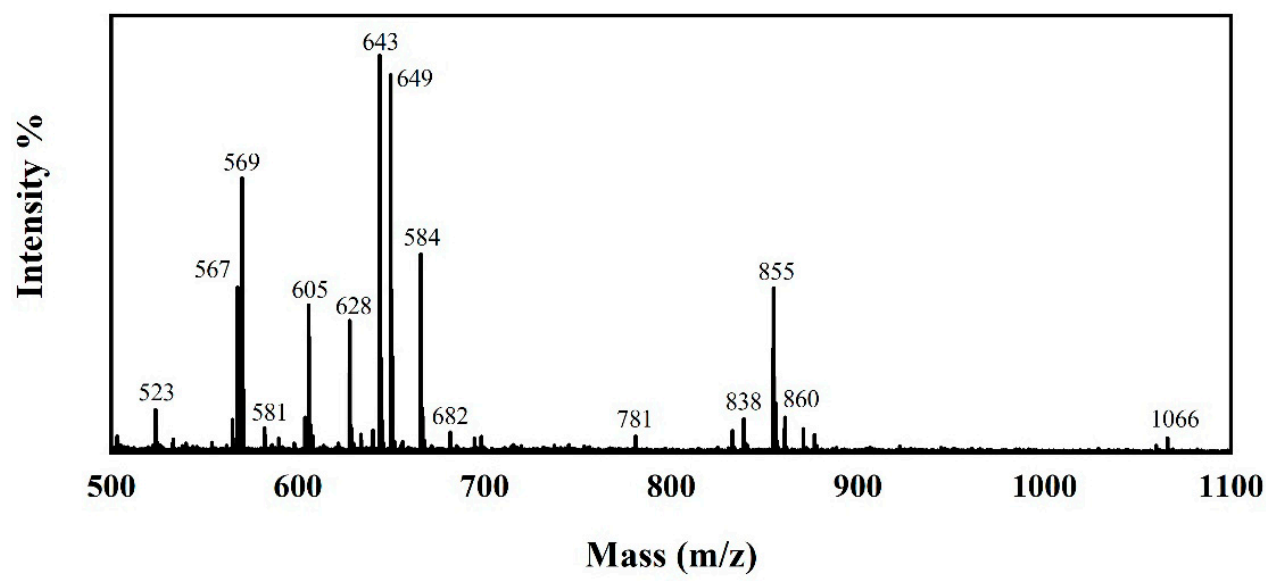

Figure 17. The MS spectra of the friction-tested aluminum plates lubricated using the 2\% JD2000 aqueous solution.

The wear marks obtained by lubrication with the distilled water and $2 \mathrm{wt.} \%$ JD2000 under the same test conditions of the aluminum plates were analyzed using EDS, and the different element contents of the friction film were obtained. The results are shown in Table 2. When the distilled water was used as the lubricating fluid, the content of $\mathrm{Al}$ in the wear mark was as great as $74.2 \%$, which is the primary component of the wear mark surface. In addition, it also contained a small amount of $\mathrm{O}$ and $\mathrm{Mg}$, which came from the water and friction material, respectively. When the JD2000 was added into the water, the primary elements of the abrasion mark were $\mathrm{Al}, \mathrm{O}$, and $\mathrm{C}$, and a portion of the $\mathrm{C}$ and $\mathrm{O}$ elements came from the JD2000. In addition, the primary composition of the friction film on the aluminum plate was the stable chemical bond, which formed due to the reaction of the $\mathrm{O}$ and $\mathrm{C}$ elements in the JD2000 with the metal surface.

Table 2. Element contents of the friction-tested aluminum plate.

\begin{tabular}{ccccc}
\hline Statistics (wt.\%) & O & Mg & Al & C \\
\hline worn surfaces under distilled water & 23.25 & 2.56 & 74.20 & 0 \\
worn surfaces under 2 wt.\% JD2000 aqueous solution & 30.33 & 1.40 & 44.35 & 23.82 \\
\hline
\end{tabular}

To further investigate the chemical composition of the tribofilms and describe the lubrication mechanism of the JD2000, the compositions of the wear marks on the aluminum plates after the friction test were analyzed using XPS. Figure 18 shows the high-resolution XPS spectra of O1s, Al2p, C1s and N1s, illustrating the changes in the chemical states of several typical elements on the worn surfaces. All the high-resolution XPS spectra were fitted using the Lorentzian-Gaussian method. The Al2p and O1s spectra of the worn surfaces under the two lubrication types were analogous. The weak peaks at $74.2 \mathrm{eV}$ for Al2p and A12p signal intensity of the JD2000 were slightly stronger, which came from the reaction of the $\mathrm{Al}$ element with $\mathrm{O}$ during the friction process. The $\mathrm{O}$ in the JD2000 molecule promoted the formation of a more stable $\mathrm{Al}-\mathrm{O}$ bond on the metal surface. The O1s spectra of both were at $531 \mathrm{eV}$, and the signal peaks at 532.8 and $532.8 \mathrm{eV}$ were from $\mathrm{Mg}-\mathrm{O}$ and $\mathrm{Al}-\mathrm{O}$, respectively. The peak of the JD2000 was slightly higher, which indicated that the oxygen element in the JD2000 also participated in the formation of the chemical bond. The peaks of the C1s spectra of the JD2000 at 284.6 and $285.6 \mathrm{eV}$ came from the C-C and $\mathrm{C}-\mathrm{O}$ bonds, respectively. The spectra of the $\mathrm{N}$ elements showed that the active nitrogen elements in the additive reacted with aluminum to produce the binding energy peak of the $\mathrm{Al}-\mathrm{N}$ bond at $398.2 \mathrm{eV}$. This makes the long chain in the JD2000 bind tightly to the surface of the steel plate during the friction process and play a protective role in preventing direct contact between the metal friction pairs. This demonstrated that the long chain structure 
of the JD2000 molecules was part of the friction film, which filled in the wear marks and played a protective role during the friction process.
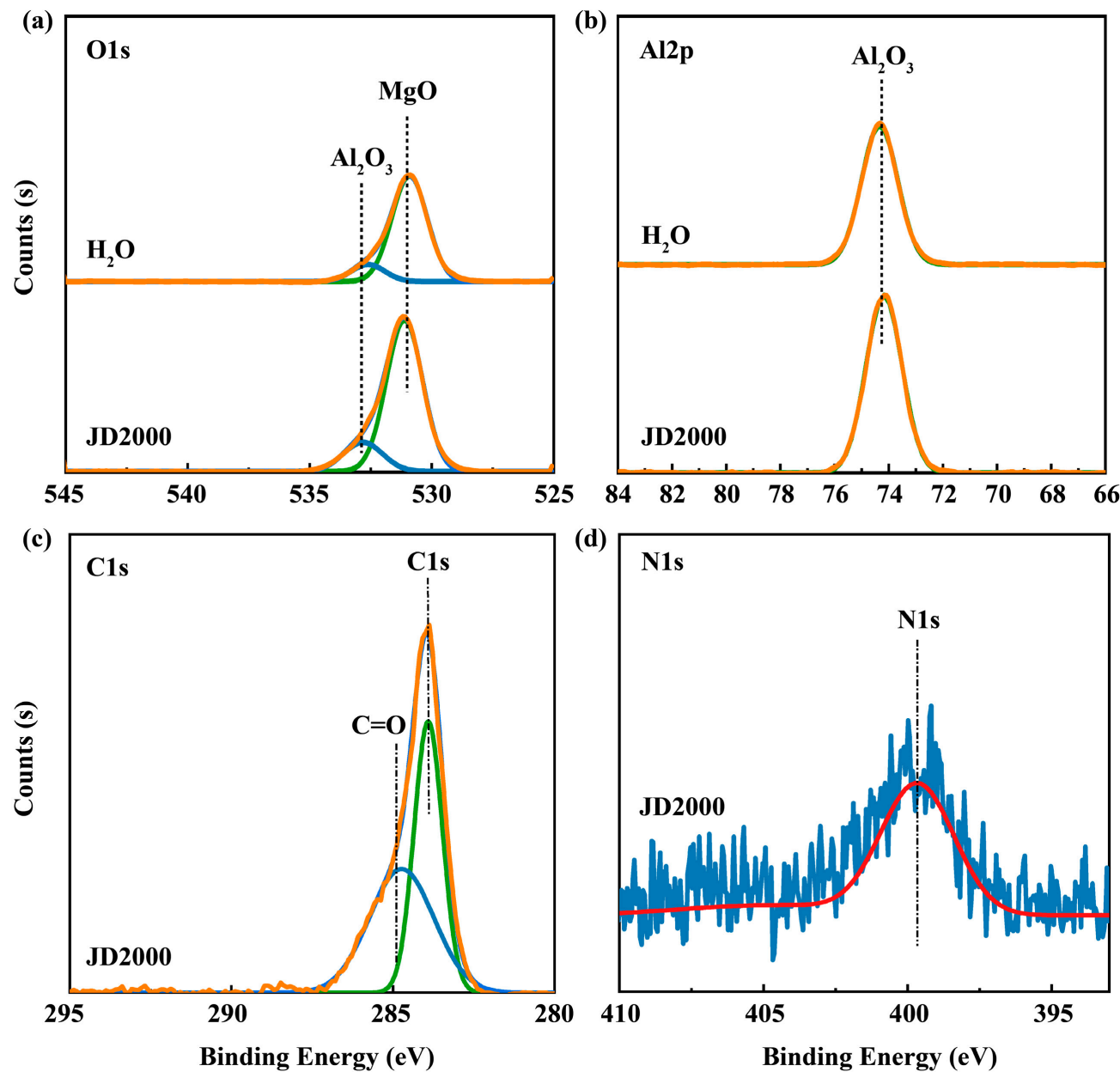

Figure 18. The XPS spectra of (a) O1s, (b) Al2p, (c) C1s and (d) N1s on the wear scar of the aluminum ball lubricated using the $2 \mathrm{wt}$.\% JD2000 aqueous solution as measured using the UMT tribometer.

\section{Discussion}

Based on the presence of tribo-oxides on the worn surfaces, the essential wear mechanism of this study was oxidative wear [17]. In the oxidative wear mechanism, the metal surface under mild wear condition had a typical single-layer of tribo-oxides. Under severe wear condition, the multilayer layers of tribo-oxides were sheared off from the surface during the friction process, leading to large plastic deformation. In this study, the worn surface lubricated by distilled water suffered wide furrows and severe plastic deformation, resulting in the weak XPS signals of $\mathrm{Fe}_{2} \mathrm{O}_{3}$ and $\mathrm{SiO}_{2}$ on the surface from steel plates and aluminum plates [18]. It can be speculated that the multilayer tribo-oxides detached from the worn surface during sliding. The addition of the JD2000 led to the slight scratches and few plastic deformation, and the strong XPS signals of oxides and nitrides were detected on the surface. The QCM-D test confirmed the formation of viscoelastic film by studying the adsorption behavior of the JD2000 molecules on metal surface. The measurement of water contact angle further confirmed that the JD2000 molecules can achieve stable adsorption on the metal surface through active nitrogen element. The MS test results show that the adsorption membrane contains a large number of polymers of different molecular weights. Therefore, combining multiple test results, the lubrication and anti-rust mechanism of the JD2000 can be obtained. The schematic diagram is shown in Figure 19. It can be hypothesized that the molecules of the JD2000 can be adsorbed on the metal surface by the active element $\mathrm{N}$, and the long-chain molecules can well cover the surface of the plate under 
the appropriate concentration to form a stable tribofilms and prevent direct contact with rough surfaces. In this situation, the friction state is boundary friction. The shear action appears on the lubricating film to keep the minimum friction coefficient. It also effectively reduces the occurrence of groove and abrasive wear, which can obtain a smoother surface. Therefore, compared with other water-based lubricants, the JD2000 has excellent lubrication performance. Xiangyuan Ye et al. [19] prepared a functionalized fluorinated graphene, which can only reduce the wear volume by $64 \%$ compared with that of the distilled water. The water solid carbon nanotube prepared by Xiaowei Pei et al. [20] can reduce the wear volume and COF by $40 \%$ and $46 \%$, respectively. At the same time, the dense protective film can resist the corrosion of the surrounding media and delay the corrosion reaction. Most of the water-based additives have no obvious anti-rust performance and even accelerate the corrosion of metals.
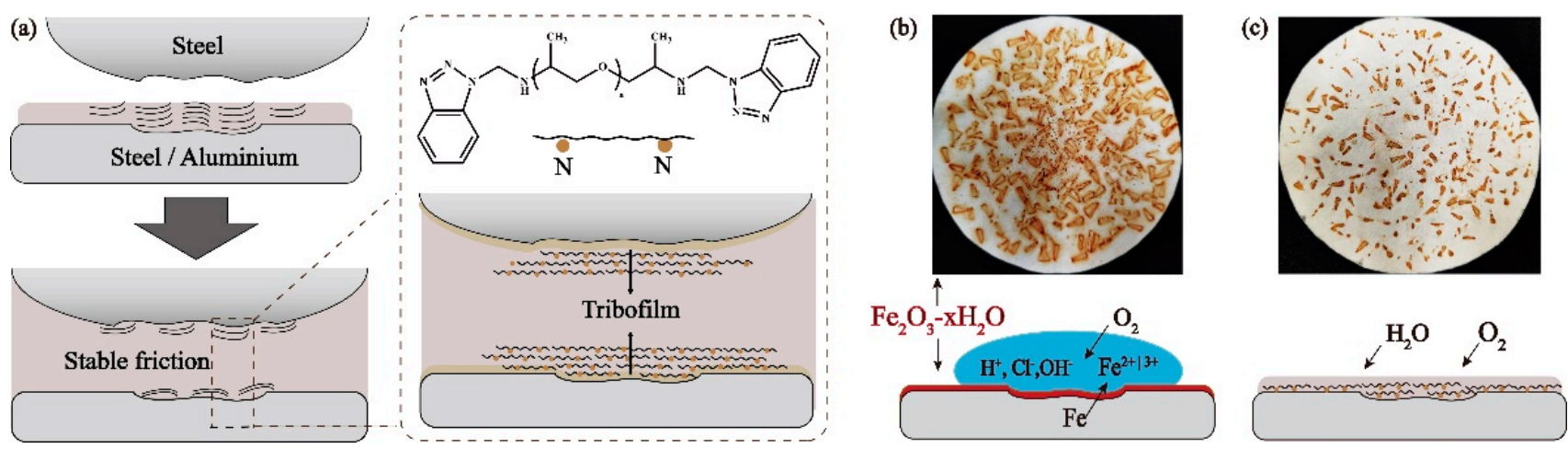

Figure 19. (a) Lubrication mechanism; (b) corrosion mechanism; and (c) anti-rust mechanism.

\section{Conclusions}

In this study, a polyether Jeffamine-triazole derivative which can be used as a waterbased multifunctional ecofriendly lubricant additive on different material surfaces was synthesized, characterized, and investigated. The following conclusions can be drawn.

1. The preparation method is simple, and the raw materials are cheap and accessible. The product can exert the excellent properties of raw materials without environmental pollution. Therefore, it can be used as an ecofriendly water-based additive.

2. The JD2000 was proved to be a multifunctional additive. It has excellent tribological properties compared with other water-based lubricants. The addition of the $2 \mathrm{wt.} \%$ JD2000 led to a reduction of $72.7 \%$ and $70.2 \%$ in friction for steel/steel and steel/aluminum contacts, respectively, relative to the distilled water, and the wear volume of the JD2000 reduced by $88.2 \%$ for steel/aluminum contact. The test also improved the anti-rust property of the JD2000 by $75.5 \%$, while some water-based lubricants do not reduce or even enhance the degree of metal corrosion.

3. The adsorption behavior of the JD2000 on metal surface and the formation of viscoelastic film were confirmed by adsorption behavior test and water contact angle tests. Worn surface analysis further determined the structure of tribofilms, which were composed of nitrogen-containing substances, metal oxides, and even polymer deposition. It is speculated that the nitrogen atoms in the JD2000 are first adsorbed on the metal surfaces and then form tribofilms. As the third body, the tribofilms improve the tribological properties by preventing straight asperity contact from the sliding surfaces. Meanwhile, this stable viscoelastic film can resist the corrosion of the metal from the external environment and reduce the corrosion degree of the metal.

4. This research can broaden the application of this Jeffamine-triazole derivative in the additives field and validates its application potential as a water-based lubricating and anti-rust additive on different metal surfaces. Concurrently, it also provides an effective method for the preparation and application of an ecofriendly water-soluble polymer-based additive. 
Author Contributions: Conceptualization, J.W. and W.H.; methodology, J.W. and W.H.; validation, J.W.; formal analysis, J.W.; investigation, J.W.; data curation, J.W.; writing-original draft preparation, J.W.; and writing-review and editing, J.W., W.H., and J.L. All authors have read and agreed to the published version of the manuscript.

Funding: This research was funded by the Youth Innovation Promotion Association, Chinese Academy of Sciences (2019288), and Shanghai Pudong New Area Science and Technology Development Fund (PKJ2019-C01).

Institutional Review Board Statement: Not applicable.

Informed Consent Statement: Not applicable.

Data Availability Statement: Data is contained within the article.

Conflicts of Interest: The authors declare no conflict of interest.

\section{References}

1. Raviv, U.; Giasson, S.; Kampf, N.; Gohy, J.F.; Jérôme, R.; Klein, J. Lubrication by charged polymers. Nature 2003, 425, 163-165. [CrossRef] [PubMed]

2. Hirano, M.; Shinjo, K.; Kaneko, R.; Murata, Y. Observation of super lubricity by scanning tunneling microscopy. Phys. Rev. Lett. 2007, 78, 1448-1451. [CrossRef]

3. Hu, W.J.; Zhang, Z.J.; Zeng, X.Q.; Li, J.S. Correlation between the degree of alkylation and tribological properties of amino-PEG2amine-based organic friction modifiers. Ind. Eng. Chem. Res. 2020, 59, 215-225. [CrossRef]

4. Ma, Z.Z.; Zhang, C.H.; Luo, J.B. Superlubricity of a mixed aqueous solution. Chin. Phys. Lett. 2011, $28,056201$.

5. Shen, M.W.; Luo, J.B.; Wen, S.Z. The tribological properties of oils added with diamond nano-particles. Tribol. Trans. 2001, 44, 494-498. [CrossRef]

6. Peng, D.X.; Kang, Y.; Chen, C.H.; Chen, S.K.; Shu, F.C. The tribological behavior of modified diamond nanoparticles in liquid paraffin. Ind. Lubr. Tribol. 2009, 61, 213-219. [CrossRef]

7. Cheng, G.G.; Jiang, S.Y.; Khosla, T.; Pesika, N.S.; Ding, J.N.; Zhang, Y.H. Synthesis of hard carbon iron microspheres and their aqueous based tribological performance under magnetic field. Tribol. Lett. 2016, 64, 48. [CrossRef]

8. Hu, W.J.; Xu, Y.H.; Zeng, X.Q.; Li, J.S. Alkyl-ethylene amines as effective organic friction modifiers for the boundary lubrication regime. Langmuir 2020, 36, 6716-6727. [CrossRef] [PubMed]

9. Chu, H.Y.; Hsu, W.C.; Lin, J.F. The anti-scuffing performance of diamond nano-particles as an oil additive. Wear. 2010, 268, 960-967. [CrossRef]

10. Ghosh, S.; Rao, P.V. Comparison between sustainable cryogenic techniques and nano-MQL cooling mode in turning of nickelbased alloy. Clean. Prod. 2019, 231, 1036-1049.

11. Desari, B.Z.; Davoobi, D. Assessing the lubrication performance of vegetable oil-based nano-lubricants for environmentally conscious metal forming processe. Clean. Prod. 2016, 135, 1198-1209. [CrossRef]

12. Huang, S.Q.; Wang, Z.; Yao, W.Q.; Xu, X.F. Tribological evaluation of contact- charged electrostatic spray lubrication as a new near-dry machining technique. Tribol. Int. 2015, 91, 74-84. [CrossRef]

13. Desanker, M.; He, X.; Lu, J.; Liu, P.; Pickens, D.B.; Delferro, M.; Marks, T.J.; Chung, Y.W.; Wang, Q.J. Alkyl-cyclens as effective sulfur- and phosphorus-free friction modifiers for boundary lubrication. ACS Appl. Mater. Interfaces 2017, 9, 9118-9125. [CrossRef] [PubMed]

14. Huang, S.; Lv, T.; Wang, M.; Xu, X. Effects of machining and oil mist parameters on electrostatic minimum quantity lubricationEMQL turning process. Int. J. Pr. Eng. Man-GT. 2018, 5, 317-326. [CrossRef]

15. Waits, C.M.; Geil, B.; Ghodssi, R. Encapsulated ball bearings for rotary micromachines. Micromech. Microeng. 2007, 17, 224-229. [CrossRef]

16. Alazemi, A.A.; Etacheri, V.; Dysart, A.D.; Stacke, L.E.; Pol, V.G.; Sadeghi, F. Ultrasmooth submicrometer carbon spheres as lubricant additives for friction and wear reduction. Appl. Mater. Int. 2015, 7, 5514-5521. [CrossRef] [PubMed]

17. Soltanahmadi, S.; Esfahani, E.A.; Nedelcu, I.; Morina, A.; van Eijk, M.C.P.; Neville, A. Surface reaction films from amine-based organic friction modifiers and their influence on surface fatigue and friction. Tribol. Lett. 2019, 67, 1-15. [CrossRef]

18. FShin, Y.; Wang, L.Q.; Bae, I.T.; Arey, B.W.; Exarhos, G.J. Hydrothermal syntheses of colloidal carbon spheres from cyclodextrins. Phys. Chem. 2008, 12, 14236-14239.

19. Xiang, Y.Y.; Li, M.M.; Zhi, G.Y.; Jin, Q.W.; Hong, G.W.; Sheng, R.Y. Covalent functionalization of fluorinated graphene and subsequent application as water based lubricant additive. Appl. Mater. Interfaces 2016, 8, 7483-7488.

20. Xiao, W.P.; Li, T.H.; Wei, M.L.; Jing, C.H. Synthesis of water-soluble carbon nanotubes via surface initiated redox polymerization and their tribological properties as water-based lubricant additive. Eur. Polym. J. 2008, 44, 2458-2464. 